\title{
The Effects of Thermal Histories on Crystallization of Poly(ethylene terephthalate)
}

\author{
Weidong ZHANG and Deyan SHEN ${ }^{\dagger}$ \\ Institute of Chemistry, Chinese Academy of Sciences, Beijing 100080, People's Republic of China
}

(Received August 25, 1997)

\begin{abstract}
The isothermal and non-isothermal crystallization of poly(ethylene terephthalate) (PET) samples with different thermal histories, i.e., quenched from the melt and annealed below or above $T_{\mathrm{g}}$, was studied by FT-IR and DSC. Annealing glassy PET below or above $T_{\mathrm{g}}$ accelerated crystallization. The crystallization rate of PET increased with annealing temperature at the same annealing time and annealing time at the same annealing temperature. However, annealing below or above $T_{\mathrm{g}}$ had very little effect on ultimate degree of crystallinity in isothermal or non-isothermal crystallization.

KEY WORDS Crystallization / Poly(ethylene terephthalate) / Thermal Histories / Fourier Transform Infrared / Differential Scanning Calorimetry /
\end{abstract}

Recently, there has been increasing interest in the effects of thermal treatment below $T_{\mathrm{g}}$ or physical aging of amorphous polymers. The process is important because it affects a great number of mechanical, dielectric and thermal properties. ${ }^{1}$ The effects of physical aging on crystallinity and rate of crystallization of poly(ethylene terephthalate) (PET) are important.

Several glassy polymers are not homogeneous on a microscopic level. This indicates that a low ordered region is possible by annealing below $T_{\mathrm{g}}$ and grows with annealing time. ${ }^{2-7}$ Physical aging has also been observed to accelerate subsequent crystallization on heating to crystallization temperatures. ${ }^{8,9}$ In contrast, some papers report that physical aging has no effect on the rate of crystallization because heating above the glass transition immediately eliminates physical aging effects. ${ }^{4,10}$

To shed more light on this research, in situ FT-IR and DSC studies on the isothermal and non-isothermal crystallization of PET with different thermal histories, i.e., quenched from the melt and annealed below or above $T_{\mathrm{g}}$ temperature, were carried out.

\section{EXPERIMENTAL}

PET pellets were dissolved in chloroform-trifluoroacetic acid ratio $4: 1 \mathrm{v} / \mathrm{v}^{11}$ The concentrations of solution were $9 \%$. A glass plate was inserted into the solution and taken out and placed in an oven at $80^{\circ} \mathrm{C}$ to make solution cast films of $c a .10 \mu \mathrm{m}$ thick. After the solvent was evaporated, the films were placed in a vacuum oven at $40^{\circ} \mathrm{C}$ for four days to remove remaining solvent. The films were heated to $285^{\circ} \mathrm{C}$ and rapidly quenched in ice-water to get melt-quenched samples, these samples were amorphous as indicated by FT-IR and $T_{\mathrm{g}}$ were $72^{\circ} \mathrm{C}$ as determined by DSC at heating rate of $3^{\circ} \mathrm{C} \mathrm{min}^{-1}$. The melt-quenched samples were annealed at $65^{\circ} \mathrm{C}$ (below $T_{\mathrm{g}}$ ), $75^{\circ} \mathrm{C}$ (just above $T_{\mathrm{g}}$ ), and $85^{\circ} \mathrm{C}$ (above $T_{\mathrm{g}}$ ) for 48 , 72 , and $96 \mathrm{~h}$, respectively.

Thermal investigation was performed on a TA-INST 2000 system with a data station, heating rate was $3^{\circ} \mathrm{C}$ $\min ^{-1}$.

Infrared spectra in the region $750-1650 \mathrm{~cm}^{-1}$ were

$\uparrow$ To whom correspondence should be addressed. collected with a Bruker model IFS 113v FT-IR spectrometer at $2 \mathrm{~cm}^{-1}$ resolution. A liquid- $\mathrm{N}_{2}$-cooled broad band MCT detector was used. For measurements during a temperature scan from $25-180^{\circ} \mathrm{C}$, the sample was held in the heating cell at a heating rate of $1^{\circ} \mathrm{Cmin}^{-1}$. Each spectrum was the average of 64 scans.

\section{RESULTS AND DISCUSSION}

DSC curves for the samples of melt-quenched and then annealed at 65,75 , and $85^{\circ} \mathrm{C}$ each for $48 \mathrm{~h}$ for one series of experiments are shown in Figure 1. The cold-crystallization peaks shift to the lower temperatures with increasing annealing temperature at the same annealing time.

In other series of experiments the specimens were annealed at $65^{\circ} \mathrm{C}$ for 48,72 , and $96 \mathrm{~h}$. The corresponding DSC curves are shown in Figure 2. Cold-crystallization peaks also shift to lower temperature with increasing annealing time at the same temperature.

The $-\mathrm{O}-\mathrm{CH}_{2}-\mathrm{CH}_{2}-\mathrm{O}-$ moiety of a PET chain shows gauche and trans conformers through internal rotation

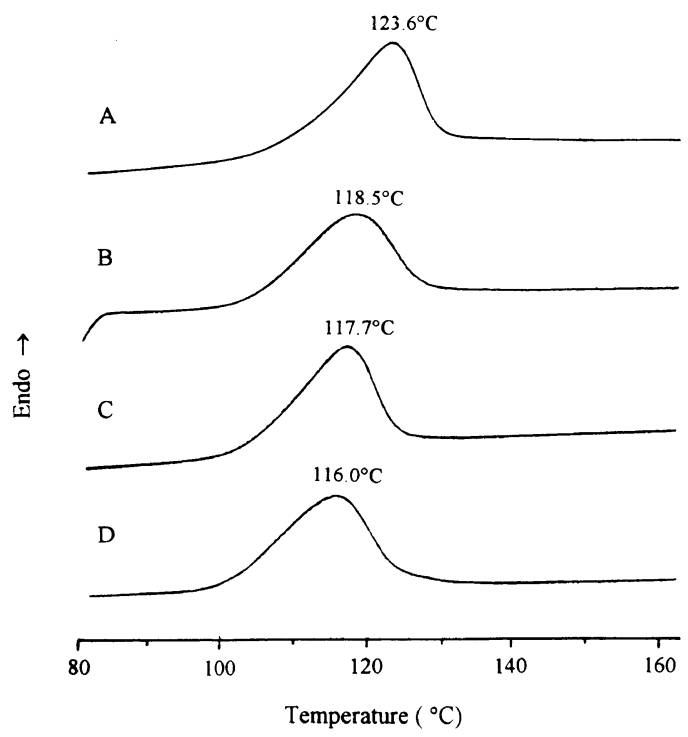

Figure 1. DSC curves for the four samples of PET of different thermal histories. A, melt quenched; B, annealed at $65^{\circ} \mathrm{C}$ for $48 \mathrm{~h}$; C, annealed at $75^{\circ} \mathrm{C}$ for $48 \mathrm{~h}$; D, annealed at $85^{\circ} \mathrm{C}$ for $48 \mathrm{~h}$. 
of the $\mathrm{C}-\mathrm{C}$ band. In crystalline regions the $-\mathrm{O}-\mathrm{CH}_{2}-$ $\mathrm{CH}_{2}-\mathrm{O}-$ moiety adopts a trans conformation, while in amorphous regions it is mainly the gauche conformation and the contribution of trans conformation is small. Crystallinity can be estimated from the fraction of trans conformers of PET. ${ }^{12,13}$ A number of studies has appeared for the infrared spectroscopic characterization of contributing conformers of the PET chain. ${ }^{3,14-18}$ In the infrared spectrum of PET the $1340 \mathrm{~cm}^{-1}$ and 1370 $\mathrm{cm}^{-1}$ bands have been assigned to the $\mathrm{CH}_{2}$ wagging

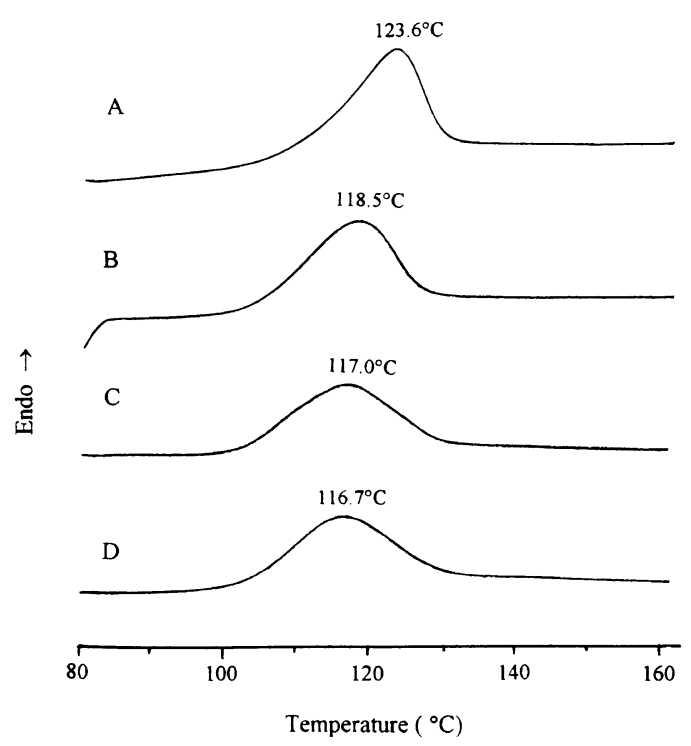

Figure 2. DSC curves for the four samples of PET of different thermal histories. A, melt quenched; B, annealed at $65^{\circ} \mathrm{C}$ for $48 \mathrm{~h}$; C, annealed at $65^{\circ} \mathrm{C}$ for $72 \mathrm{~h} ; \mathrm{D}$, annealed at $65^{\circ} \mathrm{C}$ for $96 \mathrm{~h}$.
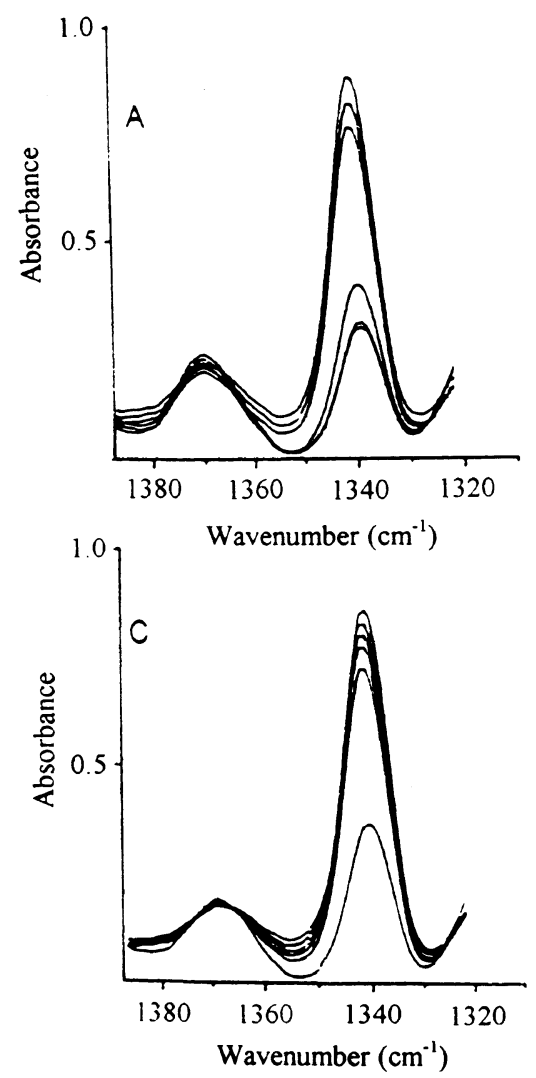

mode in trans and gauche conformers, respectively. ${ }^{16}$ As the intensities of these two bands are comparable in the spectrum of amorphous PET, we choose these two bands as key bands for determining the relative conformational population. The fractions of trans $(T)$ and gauche $(G)$ conformers can be obtained by ${ }^{6}$

$$
T=A_{1340} /\left(A_{1340}+6.6 \times A_{1370}\right)
$$

and

$$
G=6.6 \times A_{1370} /\left(A_{1340}+6.6 \times A_{1370}\right)
$$

where $A_{1340}$ and $A_{1370}$ are the integral absorbances of the $1340 \mathrm{~cm}^{-1}$ and the $1370 \mathrm{~cm}^{-1}$ bands, respectively.

The in situ infrared spectra (in the region 1320-1390 $\mathrm{cm}^{-1}$ ) on heating at $1^{\circ} \mathrm{Cmin}^{-1}$ for the four samples of different thermal histories, A (melt-quenched), B (annealed at $65^{\circ} \mathrm{C}$ for $48 \mathrm{~h}$ ), C (annealed at $75^{\circ} \mathrm{C}$ for $48 \mathrm{~h}$ ), and D (annealed at $85^{\circ} \mathrm{C}$ for $48 \mathrm{~h}$ ) are shown in Figure 3, respectively. Changes of the fraction of trans conformers with increasing temperature are shown in Figure 4. The results clearly indicate that the coldcrystallization starting temperatures shift to lower temperature at the same annealing time with increasing temperature. This is consistent with DSC measurements (Figure 1). Siegmann and Turi ${ }^{9}$ indicate that annealing below $T_{\mathrm{g}}$ probably results in ordered sequences of trans structures in amorphous PET. The low ordered regions in the system grow with annealing temperature and time. So increasing annealing temperature accelerates thermal crystallization and makes the cold-crystallization temperature decrease.

Changes of the fraction of trans conformers of the

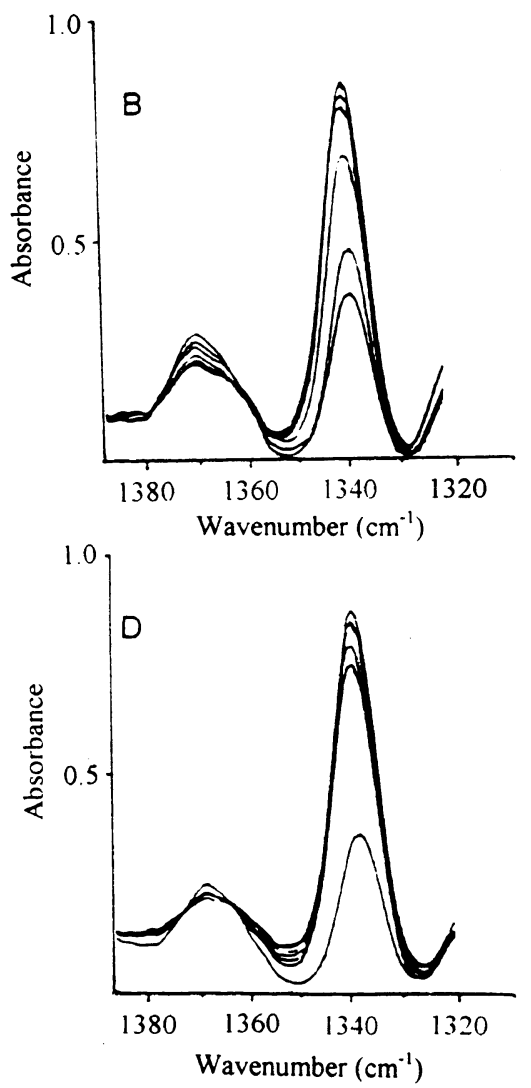

Figure 3. Comparison of infrared spectra in $1320-1390 \mathrm{~cm}^{-1}$ region of PET samples with different thermal histories as a function of temperature. A, melt quenched; B, annealed at $65^{\circ} \mathrm{C}$ for $48 \mathrm{~h}$; C, annealed at $75^{\circ} \mathrm{C}$ for $48 \mathrm{~h}$; D, annealed at $85^{\circ} \mathrm{C}$ for $48 \mathrm{~h}$. From bottom to top, measured temperatures of the spectra are $110,120,130,140,150,160^{\circ} \mathrm{C}$, respectively. 


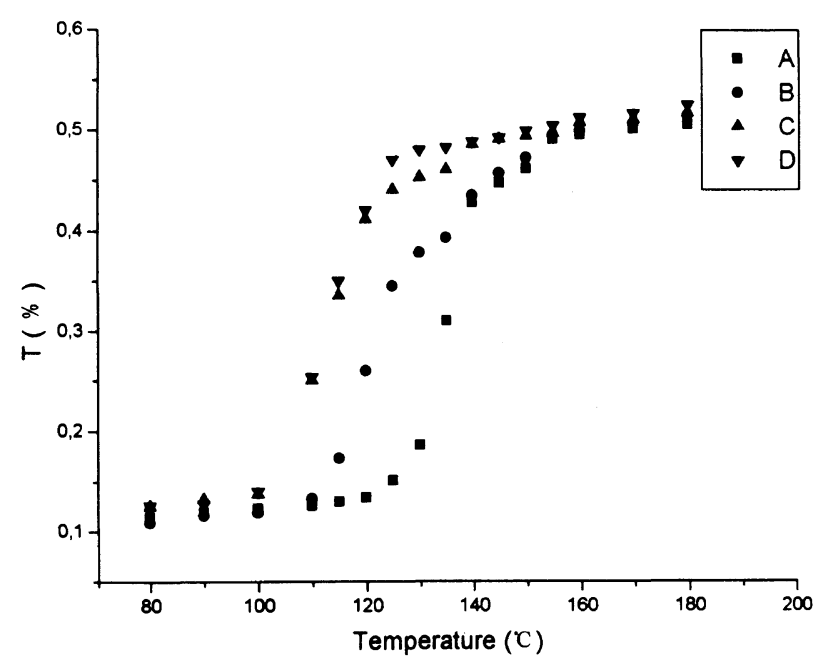

Figure 4. Changes of the fraction of trans conformers of PET samples with different thermal histories as a function of temperature. A, melt quenched; $\mathrm{B}$, annealed at $65^{\circ} \mathrm{C}$ for $48 \mathrm{~h}$; C, annealed at $75^{\circ} \mathrm{C}$ for $48 \mathrm{~h} ; \mathrm{D}$, annealed at $85^{\circ} \mathrm{C}$ for $48 \mathrm{~h}$.

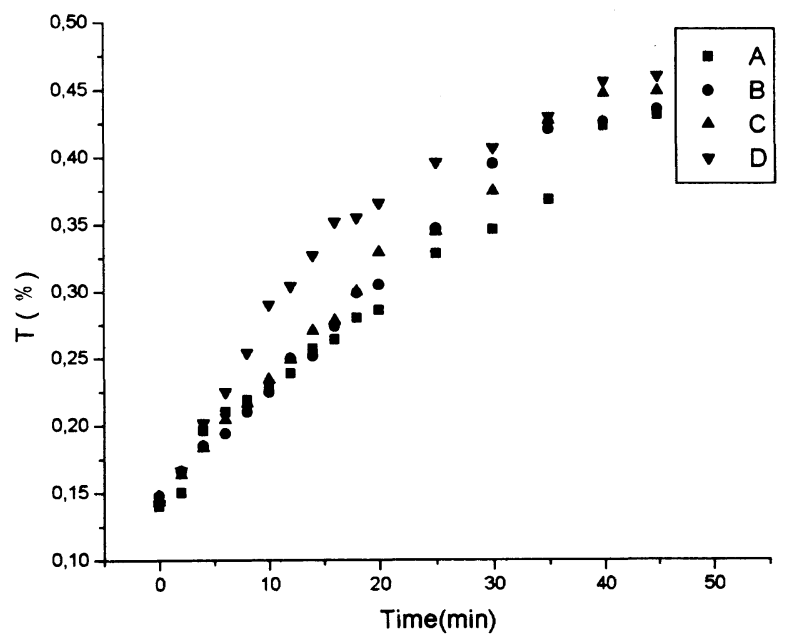

Figure 5. Changes of the fraction of trans conformers of PET samples with different thermal histories as a function of time of isothermal crystallization at $110^{\circ} \mathrm{C}$. A, melt quenched; B, annealed at $65^{\circ} \mathrm{C}$ for $48 \mathrm{~h} ; \mathrm{C}$, annealed at $75^{\circ} \mathrm{C}$ for $48 \mathrm{~h} ; \mathrm{D}$, annealed at $85^{\circ} \mathrm{C}$ for $48 \mathrm{~h}$.

samples A, B, C, and D as a function of time of isothermal crystallization at $110^{\circ} \mathrm{C}$ are shown in Figure 5. Although the crystallization of annealed samples is faster than that of quenched one, when the time of crystallization is long enough, the degrees of crystallinity are nearly identical.

The rate of isothermal crystallization at any temperature can be shown by the Avrami equation ${ }^{19,20}$

$$
1-X_{t} / X_{\infty}=\exp \left(-k t^{n}\right)
$$

where $X_{t}$ is the crystallinity of the sample at the time $t$, $X_{\infty}$ is that at which further increase of crystallinity with time is imperceptible, $K$ is a constant that includes the rate constants for growth and nucleation, and $n$ is a constant having a value between 1 and 4 . Here

$$
X_{t} / X_{\infty}=\left(T_{t}-T_{0}\right) /\left(T_{\infty}-T_{0}\right)
$$

where $T_{0}, T_{t}$, and $T_{\infty}$ are fractions of trans conformers at the beginning of crystallization, at time $t$ and at later periods when further increase is imperceptible.

Avrami plots for samples A, B, C, and D are shown

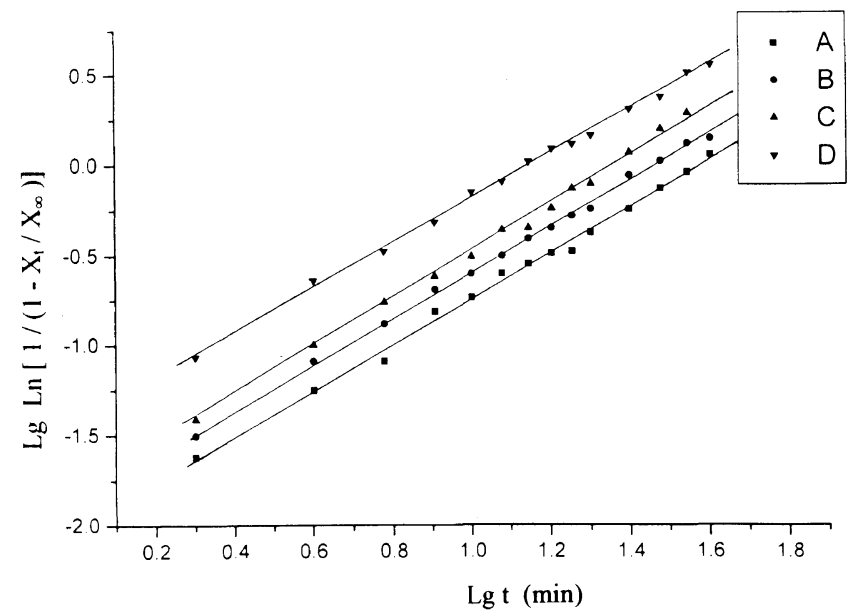

Figure 6. Avrami plots of isothermal crystallization of PET samples with different thermal histories at $110^{\circ} \mathrm{C}$. A, melt quenched; B, annealed at $65^{\circ} \mathrm{C}$ for $48 \mathrm{~h} ; \mathrm{C}$, annealed at $75^{\circ} \mathrm{C}$ for $48 \mathrm{~h} ; \mathrm{D}$, annealed at $85^{\circ} \mathrm{C}$ for $48 \mathrm{~h}$.

Table I. $\tau_{1 / 2}$ of isothermal crystallization at $110^{\circ} \mathrm{C}$

\begin{tabular}{|c|c|c|}
\hline \multirow{2}{*}{ Samples } & Annealing time & \multirow{2}{*}{$\frac{\tau_{1 / 2}}{\min }$} \\
\hline & $\mathrm{h}$ & \\
\hline Melt quenched & & 22.8 \\
\hline \multirow[t]{3}{*}{ Annealed at $65^{\circ} \mathrm{C}$} & 48 & 18.6 \\
\hline & 72 & 18.0 \\
\hline & 96 & 17.5 \\
\hline \multirow[t]{3}{*}{ Annealed at $75^{\circ} \mathrm{C}$} & 48 & 17.7 \\
\hline & 72 & 17.2 \\
\hline & 96 & 16.8 \\
\hline \multirow[t]{3}{*}{ Annealed at $85^{\circ} \mathrm{C}$} & 48 & 11.4 \\
\hline & 72 & 10.5 \\
\hline & 96 & 10.0 \\
\hline
\end{tabular}
for PET samples with different thermal histories

in Figure 6. The plots of the four samples are all linear with similar slopes and different constants $K$ (i.e., different crystallization rate). When

$$
X_{t} / X_{\infty}=1 / 2
$$

the half time of crystallization $\tau_{1 / 2}$, the time required to attain one half $T_{\infty}-T_{0}$, can be obtained, so the rate of crystallization can be found by $\tau_{1 / 2}$.

$\tau_{1 / 2}$ of isothermal crystallization at $110^{\circ} \mathrm{C}$ for PET samples with different thermal histories are listed in Table I. $\tau_{1 / 2}$ decrease with increasing annealing temperature at the same annealing time and increasing annealing time at the same temperature.

Annealing glassy PET below or above $T_{\mathrm{g}}$ does indeed affect structure and probably results in local parallel alignment of neighbouring chain segments in the system. ${ }^{3,6,7}$ Some of the ordered regions can act as nuclei for later crystallization, and others are incorporated into crystals as they grow. So annealing glassy PET below or above $T_{\mathrm{g}}$ accelerates crystallization. As the crystallization temperature increases, the mobility of the polymer chains increases and the ordered structure is destroyed. Moreover when crystallization time is long enough, the ordered structure relaxes gradually. So annealing below or above $T_{\mathrm{g}}$ has very little effect on ultimate degree of crystallinity in isothermal or non-isothermal crystallization. 


\section{CONCLUSIONS}

In situ FT-IR and DSC studies on the isothermal and non-isothermal crystallization of PET with different thermal histories, i.e., quenched from the melt and annealed below or above $T_{\mathrm{g}}$ temperature, were carried out.

1. Annealing below or above $T_{\mathrm{g}}$ probably results in local parallel alignment of neighbouring chain segments in the system and accelerates the crystallization.

2. The crystallization rate of PET increases with annealing temperature at the same annealing time and with annealing time at same temperature.

3. Annealing below or above $T_{\mathrm{g}}$ has very little effect on ultimate degree of crystallinity in isothermal or nonisothermal crystallization.

Acknowledgment. This work was supported by the National Basic Research Project-Macromolecule Condensed State.

\section{REFERENCES}

1. L. C. E. Struik, "Physical Aging in Amorphous Polymers and Other Materials," Elsevier, Amsterdam, 1978.

2. A. Siegmann and P. H. Geil, J. Macromol. Sci., Phys., B4, 239
(1970).

3. L. D'Esposito and J. L. Koenig, J. Polym. Sci., Polym. Phys. Ed., 14, 1731 (1976).

4. E. Ito, K. Yamamoto, Y. Kobayashi, and T. Hatakeyama, Polymer, 19, 39 (1978).

5. H. H. Song and R. J. Roe, Macromolecules, 20, 2723 (1987).

6. R. Qian, D. Shen, and F. Sun, Macromol. Chem. Phys., 197, 1485 (1996).

7. Y. Wang, D. Shen, and R. Qian, J. Polym. Sci., Polym. Phys. $E d$., in press.

8. P. J. Harget and A. Siegmann, J. Appl. Phys., 43, 4357 (1972).

9. A. Siegmann and E. Turi, J. Macromol. Sci., Phys., B10, 689 (1974).

10. A. Aref-Azar and J. N. Hay, Polymer, 23, 1129 (1982).

11. H. Li and D. Shen, Acta Polymerica Sinica, 100 (1992).

12. P. G. Schmidt, J. Polym. Sci., A1, 1271 (1963).

13. S. B. Lin and J. L. Koeing, J. Polym. Sci., Polym. Phys. Ed., 21 , 2365 (1983).

14. I. M. Ward, Chem. Ind. (London), 905 (1956); ibid., 1102 (1957).

15. A. Miyake, J. Polym. Sci., 38, 479 (1959).

16. F. J. Boerio, S. K. Bahl, and G. E. McGraw, J. Polym. Sci., Polym. Phys. Ed., 14, 1029 (1976).

17. D. Shen, X. Yang, S. Zhu, Q. Wu, and Z. Wen, Gaofenzi Tongxun, $209(1980)$

18. X. Yang, F. Long, D. Shen, and R. Qian, Polym. Commun., 32, 125 (1991).

19. A. D. Jenkins, "Polymer Science-A Materials Science Handbook," Vol. 1, North-Holland Publishing Co., London, 1972, Chapter 4.

20. R. Qian, J. He, and D. Shen, Polym. J., 19, 461 (1987). 